DOI: 10.12731/2218-7405-2018-3-28-51

УДК 373.3/5(075.8)

\title{
КОМПЛЕКСНЫЙ ПОДХОД В ПРЕОДОЛЕНИИ НАРУШЕНИЙ РЕЧИ У ДЕТЕЙ С РАССТРОЙСТВАМИ АУТИСТИЧЕСКОГО СПЕКТРА
}

\author{
Чигинцева Е.Г., Сунагатуллина И.И., Исаева Е.В., \\ Аболмасова Л.С.
}

Цель. Статья посвящена проблеме преодоления нарушений речи у детей с расстройствами аутистического спектра (РАC). Предметом анализа выступают различные подходы к работе по речевому развитию детей с данной категорией нарушения. Автор ставит иелью рассмотреть комплексный подход в преодолении речевых нарушений у детей с РАС.

Метод или методология проведения работы. Основу исследования образуют методы зарубежных и российских школ, такие как «Терапия объятий», ТЕАССН-подход эмоционально-уровневый, поведенческий подходы, комментирование, эмочиональное заражение, психодрама, игротерапия, арттерапия, музыкотерапия, обсуждение жсизненных ситуаций и книг, сочинение сказок и историй, различные приемы релаксации.

Результаты. Результаты работы заключаются в том, что выявленный в данной работе показатель прироста количественно-качественных показателей доказывает, что эффективность коррекционно-педагогической работы по преодолению системного недоразвития речи у детей с РАС зависит от того, насколько было соблюдено условие комплексного подхода, т. е. объединены усилия специалистов различного профиля, произошло ли слияние различных методик по работе с аутистами, насколько качественной была организачия микросочиума (семья, ДОУ, группа сверстников, спортивныле секции и т.д.).

Область применения результатов. Результаты исследования могут быть использованы в коррекицонно-развивающей работе с детьми с расстройствами аутистического спектра. 
Ключевые слова: расстройства аутистического спектра; нарушения речи; комплексный подход; аутизащия; сенсорные игрушки.

\section{COMPREHENSIVE APPROACH IN OVERCOMING VICTIMS OF SPEECH IN CHILDREN WITH DISTINCTIONS OF THE AUTHENTIC SPECTRUM}

\section{Chigintseva E.G., Sunagatullina I.I., Isayeva E.V., Abolmasova L.S.}

Purpose. The article is devoted to the problem of overcoming speech disorders in children with autism spectrum disorders (RAS). The subject of the analysis are different approaches to the work on the speech development of children with this category of violation. The author seeks to consider a comprehensive approach in overcoming speech disorders in children with $R A S$.

Methodology. The basis of the study is the methods of foreign and Russian schools, such as "Embrace therapy", the TEASS approach, emotional-level, behavioral approaches, commenting, emotional contamination, psychodrama, game therapy, art therapy, music therapy, discussion of life situations and books, writing fairy tales and stories, various relaxation techniques.

Results. The results of the work consist in the fact that the indicator of the increase in quantitative and qualitative indicators revealed in this study proves that the effectiveness of corrective pedagogical work on overcoming the systemic speech underdevelopment in children with RAS depends on whether the condition of the integrated approach was met, that is, the efforts of specialists of various profiles, whether there was a merger of various techniques for working with autistics, how good was the organization of the microsocium (family, DOW, peer group, sports projections, etc.).

Practical implications. The results of the study can be used in corrective-developing work with children with autism spectrum disorders.

Keywords: autism spectrum disorders; speech disorders; complex approach; autism; sensory toys. 


\section{Введение}

Специалисты Всемирной организации здравоохранения подчеркивают, что аутизмом страдают люди на всех континентах, во всех странах, независимо от пола, расовой принадлежности и социально-экономического положения. Озабоченность ученых вызывает тот факт, что статистика распространенности данного расстройства раннего развития человека за последние десять лет выросла в 10 раз. Сегодня научному сообществу уже понятно - проблема увеличения количества детей, имеющих проявления аутизма или расстройства аутистического спектра (РАС), намного масштабнее и сложнее, чем казалось сначала. В последние годы общеупотребительным стал термин «расстройства аутистического спектра» (PAC), к которым помимо детского аутизма (F84.0) относят атипичный аутизм (F84.1) и синдром Аспергера (F84.5). Некоторые исследователи включают в РАС и психогенные формы с аутистическим поведением.

Проявления речевых и неречевых расстройств у детей с аутизмом чрезвычайно многообразны и отличаются различной степенью выраженности [6]. Исследования нарушений речи у детей с аутизмом проводились отечественными дефектологами и психиатрами в трех направлениях: клинико-психологическом (О.С. Никольская и др., 1997), педагогическом (С.С. Морозова, 1990) и клиническом (Е.М. Мастюкова, Р.К. Ульянова, 1990). Также вопросами коррекции аутизма занимались К.С Лебединская, В.В. Лебединский (1985 год), И.И. Мамайчук (2007 год) [15].

До недавнего времени российские исследователи использовали термин «ранний детский аутизм» (РДА). Данное нарушение изучается, в основном, у детей и описывается как один из основных симптомов при шизофреническом процессе, иногда при органической патологии мозга. Однако междисциплинарные исследования в области аутизма, проведенные в последние десятилетия, привели к терминологическим изменениям [11]. Оказалось, что детский аутизм может впервые проявляться клинически в 3-5 лет, а возможно (при некоторых формах) и старше. Более того, по мнению ведущих мировых диагностических систем МКБ-10 (1) и DSM IV можно говорить 
и об аутизме взрослых. Поэтому термин «расстройство аутистического спектра» (РАC), объединяющий все варианты аутистических расстройств, возник как своеобразный компромисс между теорией и практикой. В настоящее время в группу РАС принято включать разные клинические группы [4].

\section{Материалы и методы}

Расстройство аутистического спектра (РАС) - это спектр психологических характеристик, описывающих широкий круг аномального поведения и затруднений в социальном взаимодействии и коммуникациях, а также жёстко ограниченных интересов и часто повторяющихся поведенческих актов [22].

Учитывая, что РАС - диагноз полиэтиологический и полинозологический, имеющий сложные и ярко протекающие психологопедагогические и медицинские симптомы, коррекция РАС должна носить комплексный характер [12]. Одним из наиболее постоянных проявлений РАС является нарушение (недоразвитие) речи, имеющее системный характер. Это обстоятельство позволило нам утверждать, что исследование на тему комплексного подхода в преодолении системного недоразвития речи у детей с расстройствами аутистического спектра является актуальным. В контексте данной работы необходимо теоретически обосновать и практически подтвердить эффективность комплексного подхода в коррекции речевых расстройств у детей с РАС.

Проведя анализ теоретических исследований в рамках уточнения природы механизма РАС и нарушений речи в частности, можно уточнить парадоксальность проявлений поведенческих реакций ребенка. Мы поддерживаем точку зрения К.С. Лебединской и О.С. Никольской, которые рассматривают аутизм как аффективное нарушение и выделяют четыре группы аутичных детей в зависимости от тяжести и характера аутизма, степени дезадаптации ребенка и возможностей его социализации в соответствии с уровневой системой аффективной регуляции. Степень аутистического дизонтогенеза наиболее выражена у первой группы и наименее заметна у четвертой. 
В первой группе аутизация предстает как полная отрешенность от окружающего, в активное взаимодействие с окружающей средой дети не вступают, не защищаются, а ускользают, отгораживаются от внешнего мира. Такие дети, как правило, мутичны.

Во второй группе аутизация проявляется как активное отвержение мира. Дети кажутся наиболее страдающими, часто испытывают физический дискомфорт, наблюдается избирательность в еде, отягощеннность страхами. Для их речи характерны эхолалии, штампы.

У третьей группы детей аутизация проявляется как захваченностъ собственными переживаниями. Стереотипизация ситуации пережитого страха или дискомфорта - наиболее характерный симптом. Могут демонстрировать избирательный интерес в какой-то области, при этом обладают правильной, развернутой речью. Главная проблема для них - это гибкое взаимодействие со средой, диалог с людьми. Адаптация этих детей, как показывает опыт обучения, более успешна и приводит к формированию достаточно широкого спектра социально значимых навыков.

Аутизация детей четвертой группы наименее глубокая. Она выступает в виде некоторых трудностей в общении с миром и людьми и своеобразия социальных контактов. Они нуждаются в постоянной эмоциональной поддержке близких, в одобрении и ободрении со стороны взрослых. При адекватном коррекционном подходе имеют наилучший прогноз психического развития и социальной адаптации [10]. Однако, данные группы не теряют своей «синдромологичности», так как имеют стойкие сходные проявления.

Для всех групп детей общим являются:

- стремление уйти от общения

- ограничение контактов даже с близкими людьми

- неспособность играть с другими детьми

- отсутствие активного, живого интереса к окружающему миру

- стереотипность в поведении

- страхи

- агрессия и самоагрессия 
- нарушения (недоразвитие) речи или выраженное ее своеобразие (3, 4 группа).

При отсутствии адекватного лечебно-коррекционного воздействия, отмечается нарастающая с возрастом задержка речевого и интеллектуального развития, трудности в обучении (для синдромологического диагноза очень важно учитывать соотношение аутистических проявлений и возраста ребенка). Характерны сложности в освоении бытовых и социальных навыков [11].

Несмотря на широкий спектр нарушений детей с аутизмом основными причинами обращения родителей к специалистам являются особенности речевого развития, так как именно в отсутствии полноценного речевого контакта родители видят основные причины затруднений в коммуникации детей. Анамнестические данные подтверждают, что первостепенные жалобы возникают вследствие специфики речи аутичных детей.

Необходимо отметить, что отсутствие взаимодействия с окружающими у аутичных детей наблюдается с самого рождения. В анамнезе у большинства детей отмечается слабая выраженность голосовых реакций уже на первом году жизни. Как правило, отсутствуют певучее гуление, активный лепет, дети не используют лепет и жест как средство коммуникации. Отсутствует интонационная выразительность голосовых реакций, интонационно-мелодическая имитация простой фразы, не бывает попыток произнести вслед за взрослым звук или слог, к концу года не появляются типичные слова. Дети с аутизмом обычно не подчиняются речевым инструкциям и не обращают внимания на лицо говорящего, что делает ребенок с нормой развития первого года жизни. То, что в норме является основой организации речевого взаимодействия, становится объектом аутостимуляции [20]. Позже (примерно к трем годам, как это наблюдается в норме) у детей не появляется комментирующая оценочная речь, что можно наблюдать в процессе обследования и выполнения диагностических проб и заданий, как то «так, не так», «эту», «вот так»» и т.д.

Наблюдения показывают, что к возрасту 6-7 лет более трети детей с аутизмом мутичны, либо у них не сформирована функци- 
ональная речь. Они могут осуществлять некоторые элементарные попытки для коммуникации, например, укладывать руки взрослого на объект, которым они хотят манипулировать. Однако жестовая коммуникация не развивается спонтанно, а в качестве замены вербальных средств коммуникации [2].

Обращает внимания факт многочисленности особенностей речевого развития аутичных детей и индивидуальности степени их проявлений у детей, но наиболее характерными являются [14]:

1) нарушения речи как следствие задержанного развития (косноязычие, физиологическая эхолалия, бедность запаса слов и др.);

2) речевые нарушения в связи с задержанным становлением сознания Я в виде неправильного употребления местоимений и глагольных форм;

3) речевые нарушения кататонической природы (вербегерации, эхолалии, эгоцентрическая, затухающая, внутренняя речь, мутизм, скандированное, растянутое или ускоренное звукопроизношение, паралингвистические нарушения тональности, темпа, тембра речи и др.);

4) психического регресса (появление речи довербального фонематического уровня);

5) расстройства речи, связанные с патологией ассоциативного процесса (нарушения смысловой стороны речи в виде незавершенных, непоследовательных ассоциаций, контаминации).

Учитывая структуру дефекта при РАС и «ядерное» нарушение (в терминологии Л.С. Выготского), наиболее перспективным подходом в изучении причин и механизмов нарушения речи является психолингвистический. Основной причиной речевых проблем у детей с РАС ученые-психолингвисты считают отсутствие мотивации в общении аутичного ребенка. С точки зрения психолингвистики порождение речи осуществляется в три этапа: семантический, языковой и моторный. На первом этапе (семантическом) у ребенка должна возникнуть потребность (мотив) в высказывании, которая после преобразуется в замысел (т.е., что именно хочет сказать ре- 
бенок). Затем он (замысел) программируется во внутреннем плане. Уже на первом этапе у ребенка аутиста возникают сложности. Желание и заинтересованность в контакте ребенок испытывает огромное, но эта потребность именно в эмоциональном общении, а не в речевом. Аутичный ребенок избегает вербального общения, что ухудшает возможности речевого развития, его речь автономна, эгоцентрична, недостаточно связана с ситуацией и окружением; оторванность такого ребенка от мира, неспособность осознать себя, очевидно, сказывается на становление его самосознания, позднее появление в речи местоимения «Я» и других личных местоимений в первом лице [22].

Нарушения речи у детей с РАС носят системный характер, так как у данной категории детей на первый план выступают проблемы, связанные с коммуникацией, а остальные речевые проблемы являются сопутствующими [1].

Для зарубежной школы по стимулированию речи аутичных детей характерно не прямое воздействие словом, а использование вспомогательных средств, таких как налаживание эмоционального общения с матерью, замещение слов карточками и т.д [5].

Метод Марты Велш «Терапия объятий» состоит в попытке форсированного, почти насильственного, но неповреждающего образования физической связи между матерью и ребенком, т. к. именно отсутствие этой связи считается сторонниками этого метода центральным нарушением при аутизме. Причём ребёнок удерживается лицом к лицу с родителем, что позволяет наладить эмоциональный контакт. Холдинг-терапия включает в себя повторяющиеся процедуры холдинга - удержания ребенка на руках у родителей до его полного расслабления (физического и эмоционального) [24].

Andrew Bondy, Lori Frost предложили использовать карточки для стимуляции коммуникации, тем самым облегчая процесс вступления ребенка в коммуникативный акт. Целью программы PECS является побудить ребенка спонтанно начать коммуникационное взаимодействие. В основе метода лежит тот факт, что повод для общения должен предшествовать фактической речевой деятельности [26]. 
И. Ловаас использует метод АВА-терапии, или «поведенческой терапии». В основе оперантного обучения лежат исследования бихевиористов, направлено на тренинг социально-бытового поведения через отработку отдельных операций с их последующим объединением.

Основная цель: формирование социально приемлемого, желаемого поведения в тех случаях, когда оно отсутствует или имеются его нарушения [23].

Э. Шоплер предлагает обучение по программе ТЕАСCH, направленное на облегчение социально-бытовой адаптации аутичного человека с помощью зрительной организации внешней среды. Основная цель: создание условий для достижения самостоятельности и высокого качества жизни. Первичный акцент делается на формировании способности ребенка оставаться на своем месте и сосредоточиваться на задании [25].

В российской педагогике так же существует несколько подходов к коррекции речевого развития детей с РАС.

В.В. Лебединский, К.С. Лебединская, О.С. Никольская утверждают, что психологическая коррекция строится поэтапно: установление эмоционального контакта; стимуляция активности, направленной на взаимодействие; снятие страхов; купирование агрессии, самоагрессии, негативизма и других отрицательных форм поведения; формирование целенаправленного поведения.

Круг методов, которые можно использовать, определяется широко: все, что будет способствовать решению или смягчению проблем ребенка; упоминаются комментирование, эмоциональное заражение, психодрама, игротерапия, арттерапия, музыкотерапия, обсуждение жизненных ситуаций и книг, сочинение сказок и историй, различные приемы релаксации [11].

Л.Г. Нуриева предлагает использование особенностей мышления и восприятия детей с РАС. Выстраивание визуального ряда является основным условием успешности занятий с неговорящими детьми. Чем быстрее специалист приступит к обучению чтению, тем больше шансов вызвать у ребенка эхолаличное повторение звуков речи. Параллельно ведется специальная работа по преодолению артикуля- 
торной апраксии, наличие которой может служить серьезным препятствием для успешного развития речи. Но глубина аутистических расстройств не позволяет сразу приступить к воспитанию понимания ребенком обращенной к нему речи и развитию произносительной стороны речи. До начала работы над речевой функцией необходимы особые предварительные этапы работы [17].

Е.Ф. Соботович вводит понятие «растормаживание речи». В игре, и на занятиях, и, по возможности, в течение всего дня, родители и специалисты, работающие с ребенком, подхватывают его вокализации, повторяют их с его интонацией, а затем обыгрывают и превращают их в реальные слова, связывая с ситуацией [19].

О.А Румянцева, Н.Е. Старосельская на начальном этапе коррекционной работы с неговорящими детьми используют звукоподражания. Любые занятия по развитию речи у неговорящих детей начинаются с воспитания понимания обращенной к ним речи, с развития неречевых психических функций: внимания, памяти, мышления и т.д. [18].

Т.Н. Новикова - Иванцова уделяет внимание формированию слоговой структуры слова у детей с системной патологией речи, дает понятие методам формирования языковой системы (МФЯС). Ребенка учат слитно, плавно произносить слова сложной слоговой структуры изолированно, в словосочетаниях и предложениях, соблюдая количество слогов, типы слогов, их последовательность и ударность в слове. Важным аспектом формирования навыков говорения является погруженность ребенка в речевую среду [16].

C.M. Томилина использует включение логоритмики и сенсорной интеграции, в качестве основных приемов стимулирования речи ребенка. Логоритмические занятия - это методика, опирающаяся на связь слова, музыки и движения и включают в себя пальчиковые, речевые, музыкально-двигательные и коммуникативные игры. Взаимоотношения указанных компонентов могут быть разнообразными, с преобладанием одного из них. Сенсорная интеграция - это такая организация деятельности ребенка, при которой нервная система получает информацию от всех органов чувств [12]. 
Объединяя базовые позиции зарубежных и отечественных методов, можно согласиться с исследованиями Морозовой С.С., где выбор основного коррекционного подхода должен учитывать [8]:

1. Характер структуры дефекта: специфика каждого из подходов такова, что на первых этапах коррекции ставятся различные задачи, в зависимости от того, роль каких сфер психической деятельности признается ведущей в структуре дефекта. В связи с этим, представляется разумным применять эмоционально-уровневый подход при работе с детьми, у которых в клинической картине на первый план выступают аффективные нарушения, особенно, если они служат основным препятствием к общению и развитию в целом. При выраженной умственной отсталости, когда интеллектуальные нарушения играют не меньшую (а часто и большую) роль, чем эмоциональные и коммуникативные, при отсутствии у ребенка страхов и сензитивности к контакту более логичным кажется использование поведенческих методик, которые позволяют формировать предпосылки для развития интеллекта. Организационные возможности. Важно, чтобы в наличии были специалисты, владеющие методиками работы в рамках упомянутых подходов. Это условие часто оказывается невыполнимым, однако, должно соблюдаться хотя бы в некоторой степени [3].

2. Имеет значение объем предполагаемой работы: например, начинать развернутую поведенческую терапию при количестве занятий, меньшем, чем 15-20 часов индивидуальной работы в неделю, представляется неразумным.

3. Существенную роль играет то, в каких условиях будут проходить занятия - есть ли возможность выбирать их или менять. Работа с использованием ТЕАССН-подхода и поведенческой терапии (в меньшей степени) требует определенной организации пространственной среды. Если нет возможности перемещать мебель, убирать из поля зрения ребенка лишние предметы, подбирать подходящие материалы и пособия, то лучше отказаться от систематического применения этих подходов в своей работе. Эмоционально-уровневый подход также предполагает создание особой среды, которая помо- 
гает ребенку чувствовать себя комфортно, а психологу - находить возможности для взаимодействия с ребенком, однако, эти условия не столь жестки. Таким образом, при выборе коррекционного подхода необходимо учитывать организационные оставляющие ситуации, сложившейся в образовательном (медицинском, социальном, научном) учреждении.

4. Социальная ситуация развития. Чтобы решить, как работать с ребенком, необходимо проанализировать, каковы реальные и потенциальные возможности его социальной адаптации. При знакомстве с семьей должны сделать если не заключение, то хотя бы предположение о том, какое место занимает ребенок в семье, каковы ожидания родителей. Позиция родителей в отношении ребенка, требования, которые они к нему предъявляют, их готовность к сотрудничеству и участию в коррекционном процессе очень важны при выборе подхода. Если такое сотрудничество невозможно (например, в ситуации, когда родители работают, а с ребенком сидит бабушка), то лучше применять эмоционально-уровневый подход, в рамках которого основная работа ведется «здесь и сейчас». Поведенческий и ТЕАССН - подходы в большей степени рассчитаны на изменение всех сфер жизни ребенка на продолжительный срок, поэтому их применение можно начинать, если есть уверенность в том, что семья будет работать в том же направлении, что и специалисты. Однако, несмотря на это, необходимость обучения ребенка жизненно важным навыкам (например, навыкам самообслуживания; невербальной коммуникации) порой заставляет отступать от этого правила.

5. Особенности коммуникации - один из важнейших моментов при выборе коррекционного подхода. Если у ребенка есть «естественные» социально адекватные способы коммуникации, надо попытаться развивать их в рамках эмоционально-уровневого подхода.

6. Уровень развития когнитивной сферы - если предполагается наличие выраженных когнитивных нарушений, может быть показан поведенческий подход. Это связано с тем, что в рамках поведенческого подхода хорошо разработаны способы выработки навыков, необходимых в качестве предпосылок обучения. 
7. Наличие страхов и гиперсензитивности являются показаниями к использованию на начальных этапах коррекционной работы эмоционально-уровневого подхода.

Очень важно, чтобы перед началом коррекционной работы родители и специалисты пришли к единому мнению о выборе ведущего подхода.

\section{Результаты и обсуждение}

Таким образом, мы выявили основное условие эффективности коррекционной работы у детей с РАС - коррекционная работа должна носить комплексный характер. Комплексный подход к коррекции предполагает с одной стороны, слаженную работу специалистов (логопедов, дефектологов, психологов, социальных педагогов, врачейпсихиатров) и ближайшего окружения ребенка. С другой стороны, в силу системности речевого дефекта, невозможно предугадать какой именно способ коррекции поможет каждому конкретному ребенку, поэтому необходимо сочетание сильных сторон известных методов в одну единую комплексную коррекционную систему [9].

При работе в рамках комплексного подхода необходимо соблюдать следующие принципы [7]:

1. Принцип безусловного принятия ребенка.

2. Принцип опоры на положительное.

3. Принцип учета индивидуальных и возрастных особенностей.

4. Принцип опоры на зону ближайшего развития.

5. Принцип комплексности соблюдения разделов методики.

6. Принцип доступности излагаемого материала.

7. Принцип деятельностного подхода.

Так же используются следующие методы работы [7]:

1. Наблюдение за свободной игрой;

2. Эксперимент по созданию проблемных ситуаций;

3. Беседа с родителями;

4. Анализ имеющихся медицинских и психолого-педагогических заключений на ребенка.

5. Метод сенсорной интеграции. 
6. Логоритмика.

7. Метод формирования темпо-ритмической стороны речи.

8. Метод АВА-терапии.

9. Методы коррекции звукопроизношения.

10. Метод развития связной речи.

11. Методы стимулирования коммуникации.

Проанализировав теоретические и практические работы данных специалистов, учитывая их результаты работы, опираясь на медицинское обоснование сущности РАС, мы предлагаем методические рекомендации по преодолению системного недоразвития речи у детей с РАС в рамках комплексного подхода. Методические рекомендации включают в себя следующие разделы:

1. Коррекция поведения и формирование навыка «заниматься». Задачи:

- коррекция нежелательных форм поведения на занятиях и в обществе;

- выработка навыка высиживать за выполнением задания достаточно времени без порывов прервать занятие;

- выработка навыка доведения начатого до конца;

- адаптация к требованиям педагога;

- формирование положительной установки на занятие.

Приемы:

- использование ярких сенсорных игрушек, которые находятся в «волшебной корзине»;

- использование развивающих игр (сортеры, пирамидки, матрешки, мозаики, вкладыши и т.д.);

- использование природного материала (шишки, орехи, листочки, камешки, крупы, песок, соль, тесто, ракушки и т.д.);

- использование элементов АВА-терапии (угощение, согласованное с мамой) [21].

2. Переход от предметно-манипуляторной игры к игре предметно-действенной.

Задачи:

- уменьшить количество стереотипий, которые подкрепляются простыми манипуляциями с предметами; 
- перевести предметно-манипуляторную игру в предметно действенную таким образом расширить представления ребенка о социуме;

- предметно-действенная игра вынуждает ребенка спланировать действие и соблюдать данный план.

Приемы:

- переключение с монотонной манипуляторной игры к более эмоциональной действенной игре;

- использование как можно больше интересных игрушек, игра с которыми предполагает действие;

3. Формирование навыка работы с картинками.

Задачи:

- преодоление негативизма к картинкам;

- развитие сосредоточения, умения концентрировать внимание;

- коррекция гиперактивных порывов.

Приемы:

- использование объемной игрушки и предметной картинки;

- работа с предметными картинками;

- работа с разрезными картинками;

Работа с парными картинками [21].

4. Развитие сложно скоординированных движений рук и ног, развитие мелкой моторики и зрительно-моторной координации.

Задачи:

- стимулировать взаимодействие обоих полушарий в работе

- развитие мелкой моторики рук;

- формирование зрительно-моторной координации.

Приемы:

- использование логоритмики на занятиях;

- работа с пластилином, тестом, природным материалом (сенсорная интеграции);

- развитие мелкой моторики путем рисования [13].

5. Стимулирование вокализаций и звукоподражаний. Задачи:

- сформировать способность воспроизводить услышанные неречевые звуки; 
- развить фонематический слух и фонематическое восприятие. Приемы:

- пропевание по методике Новиковой-Иванцовой гласных звуков и слогов, а в последствии коротких слов;

- прописывание гласных звуков первого порядка, и попытка соединить их с согласными) [21];

6. Стимулирование активной коммуникации ребенка. Задачи:

- сформировать у ребенка мотивацию к общению;

- научить составлять предложение-просьбу, предложение-вопрос;

- соединить жесты и поведение ребенка со словом.

Приемы:

- отказ понимать ребенка по жестам;

- создание проблемных ситуаций;

- использование поощрения за речь [13].

7. Коррекция звукопроизношения.

Задачи:

- выработка воздушной струи;

- постановка правильного звука;

- автоматизация поставленного звука;

- активный контроль и использование в собственной речи.

Приемы:

- подбор наиболее приемлемых способов постановки звука;

- формирование устойчивых связей на звук [12].

8. Формирование навыка чтения, письма и счета. Задачи:

- формирование навыка чтения, письма и счета.

Приемы:

- выделение нужного количества слогов в слове;

- формирование навыка сливания слогов в слово;

- письмо печатными буквами (под диктовку, списывание);

- чтение букваря;

- обучение счету [13]. 
Для доказательства практического применения комплексного подхода нами проведен диагностический, формирующий и контрольный этап экспериментального исследования. В исследовании приняли участие 36 детей, каждый ребенок проходил до начала коррекционной работы обследование у главного психиатра области, с целью установления диагноза и определения уровня интеллектуального развития, родители детей были обследованы по методике CARS на областной психолого-медико-педагогической комиссии для определения вида дошкольного учреждения (все дети были определены в группы ОНР логопедических детских садов города), а также было проведено электроэнцефалографическое обследование мозга с целью определения активности работы головного мозга и исключения наличия очагов эпилептической активности.

Диагностика и формирующий этап проводился на базе МУ «Социально-реабилитационный центр для детей и подростков с ограниченными возможностями» (Центр), принимающий на реабилитацию детей с РАС вне зависимости от особенностей протекания болезни. В Центре созданы условия для динамического наблюдения детей с РАС и создания индивидуальной программы реабилитации для таких детей. Мы имели возможность в течение трех лет осуществлять коррекционное воздействие на детей, отслеживать промежуточную динамику в развитии детей и итоговый уровень развития детей при завершении дошкольного возраста и подготовке к поступлению в школу. С целью выявления эффективности коррекционной работы нами была проведена итоговая диагностика уровня речевого развития детей. Итоговая диагностика заключалась в комплексном обследовании речевого развития ребенка. В связи с изменениями, произошедшими в личности детей в ходе коррекционной работы, стало возможным обследование детей по традиционной схеме. Таким образом, на контрольном этапе нами использовался «протокол обследования речи» Морозовой С.С., Богдашиной О. и адаптированная нами для детей с РАС речевая карта Волковой Г.А. [22]. Опираясь на результаты контрольного эксперимента по данным методикам, мы выяснили, что некоторые дети (16 человек, 44,4\%) с РАС к кон- 
цу эксперимента продемонстрировали уровень речевого развития, сходный с состоянием речи детей при общем недоразвитии речи 3 уровня, описанном Р.Е. Левиной [6].

\section{Заключение}

Учитывая сложный в прогностическом плане характер трудностей детей, данный результат требует дальнейшего анализа с целью изучения влияния всех факторов, способствующих положительному результату.

Выявленный в данной работе показатель прироста количественно-качественных показателей доказывает то, что эффективность коррекционно-педагогической работы по преодолению системного недоразвития речи у детей с РАС зависит от того, насколько было соблюдено условие комплексного подхода, т. е. объединены усилия специалистов различного профиля, произошло ли слияние различных методик по работе с аутистами, насколько качественной была организация микросоциума (семья, ДОУ, группа сверстников, спортивные секции и т.д.).

Данный показатель доказывает, что предложенные нами методические рекомендации по преодолению СНР у детей с РАС в рамках комплексного подхода эффективны и могут быть использованы в работе логопедов, дефектологов с данной категорией детей в дошкольных учреждениях, а также в рамках реабилитационных центров.

\section{Список литературы}

1. Баенская Е.Р. Особенности раннего аффективного развития аутичного ребенка в возрасте от 0 до 1,5 лет // Дефектология. 1995. № 5. C. $76-83$.

2. Ватсон Я., Маркус Л. Диагностика и обследования детей дошкольного возраста // Диагностика и исследование аутизма. Лондон, 1988.

3. Веденина М.Ю., Окунева О.Н. Использование поведенческой терапии аутичных детей для формирования навыков бытовой адаптации. Сообщение II // Дефектология. 1997. № 3. С. 15-20. 
4. Гилберг К., Питерс Т. Аутизм: медицинские и педагогические аспекты. СПб.: ИСПиП, 1998.

5. Жуков Д.Е. Особенности картины мира детей с аутизмом. Психосоциальные проблемы психотерапии, коррекционной педагогики, спец. психологии. Изд-во Курск. гос. ун-та, 2003.

6. Зинченко В.П., Мещеякова Б.Г. Психологический словарь. М.: Педагогика-Пресс, 1999. 345 с.

7. Иванов Е.С. Спорные вопросы диагностики раннего детского аутизма // Детский аутизм: хрестоматия. СПб.: МУСиР им. Р. Валленберга, 1997.

8. Каган В.Е. Аутизм у детей. Л.: Медицина, 1981. 190 с.

9. Кревелен В. К проблеме аутизма // Детский аутизм: Хрестоматия. СПб, 1997.

10. Лебединская К.С. Ранний детский аутизм // Нарушения эмоционального развития как клинико-дефектологическая проблема. М.: НИИ дефектологии РАО, 1992.

11. Лебединская К.С., Никольская О.С. Диагностика раннего детского аутизма. М.: Просвещение, 1991.

12. Мастюкова Е.М., Ульянова Р.К. Особенности речевого развития у детей с ранним детским аутизмом, проявляющимся на фоне резидуально-органической недостаточности ЦНС // Дефектология. 1990. №5. С. 66-71.

13. Никольская О.С, Фомина Т., Цыпотан С. Ребенок с аутизмом в обычной школе. Школьный психолог, 2002.

14. Никольская О.С., Баенская Е.Р., Либлинг М.М. Аутичный ребенок: пути помощи. М.: Теревинф, 2000. 336 с.

15.Никольская О.С., Баенская Е.Р., Либлинг М.М. Аутичный ребенок. М.: Издательский центр «Академия», 2002. 480 с.

16. Новикова-Иванцова Т.Н. От слова к фразе. Книга 1. М, 2006.

17. Нуриева Л.Г. Развитие речи у аутичных детей: Методические разработки. М.: Теревинф, 2003. 160 с.

18. Румянцева (Юнтунен) О.А., Старосельская Н.Е. Начальный этап коррекционной работы с неговорящими детьми // Проблемы детской речи - 1996: материалы межвузовской конференции, СПб: Образование, 1996. 
19. Соботович Е.Ф. Речевое недоразвитие у детей и пути его коррекции (дети с нарушением интеллекта и моторной алалией). М.: Классикс стиль, 2003. 160 с.

20. Спиваковская А. Психотерапия: игра, детство, семья. М., Апрель Пресс, ЭКСМО - Пресс, 2000.

21.Шипицина Л.М. Детский аутизм. М.: Дидактика Плюс, 2001.

22. Ярошевский М. Г., Петровский А.В. Краткий психологический словарь. А.-М.: Инфра-М, 1998.

23. Lovaas I.O. Teaching Individuals with Developmental Delays: Basic Intervention Techniques, Austin, Texas: PRO-ED, Inc., 2003.

24. M. Welch «Holding-Time». N.Y., 1988.

25. Schopler E., Reichler R., Lansing M. Teaching strategies for parents and professionals. Austin, TX: PRO-ED Inc: 1980.

26. The Picture Exchange Communication System Training Manual, 2nd Edition by Lori Frost, M.S., CCC-SLP and Andy Bondy, Ph.D., 2002, $396 \mathrm{p}$.

\section{References}

1. Baenskaya E.R. Osobennosti rannego affektivnogo razvitiya autichnogo rebenka v vozraste ot 0 do 1,5 let [Features of early affective development of an autistic child aged 0 to 1.5 years]. Defectology. 1995. № 5, pp. 76-83.

2. Watson J., Markus L. Diagnostika i obsledovaniya detey doshkol'nogo vozrasta [Diagnostics and examinations of preschool children]. Diagnostika $i$ issledovanie autizma [Diagnosis and research of autism]. London, 1988.

3. Vedenina M.Yu., Okuneva O.N. Ispol'zovanie povedencheskoy terapii autichnykh detey dlya formirovaniya navykov bytovoy adaptatsii. Soobshchenie II [The use of behavioral therapy of autistic children for the formation of habits of household adaptation. Communication II]. Defectology. 1997. № 3, pp. 15-20.

4. Gilberg K., Piters T. Autizm: meditsinskie i pedagogicheskie aspekty [Autism: medical and pedagogical aspects]. SPb .: ISPiP, 1998.

5. Zhukov D.E. Osobennosti kartiny mira detey s autizmom. Psikhosotsial'nye problemy psikhoterapii, korrektsionnoy pedagogiki, spets. Psik- 
hologii [Features of the picture of the world of children with autism. Psychosocial problems of psychotherapy, correctional pedagogy, special. Psychology]. Kursk, 2003.

6. Zinchenko V.P., Meshcheyakova B.G. Psikhologicheskiy slovar [Psychological dictionary]. M.: Pedagogika-Press, 1999. 345 p.

7. Ivanov E.S. Spornye voprosy diagnostiki rannego detskogo autizma [Controversial questions of diagnosis of early childhood autism]. Detskiy autism [Children's autism]: reader. St. Petersburg, 1997.

8. Kagan V.E. Autizm u detey [Autism in children]. L.: Medicine, 1981. $190 \mathrm{pp}$.

9. Krevelen V. K probleme autizma [To the problem of autism]. Detskiy autism [Children's autism]: Anthology. SPb, 1997.

10. Lebedinskaya K.S. Ranniy detskiy autism [Early Childhood Autism]. Narusheniya emotsional'nogo razvitiya kak kliniko-defektologicheskaya problema [Impairment of Emotional Development as a Clinical-Defectological Problem]. M.: NII defektologii RAO, 1992.

11. Lebedinskaya K.S., Nikol'skaya O.S. Diagnostika rannego detskogo autizma [Diagnosis of early childhood autism]. Moscow: Education, 1991.

12. Mastyukova E.M., Ul'yanova R.K. Osobennosti rechevogo razvitiya u detey s rannim detskim autizmom, proyavlyayushchimsya na fone rezidual'no-organicheskoy nedostatochnosti TSNS [Features of speech development in children with early childhood autism, manifested against the background of a residual-organic insufficiency of the central nervous system]. Defectology. 1990. № 5, pp. 66-71.

13. Nikol'skaya O.S, Fomina T., Tsypotan S. Rebenok s autizmom v obychnoy shkole [A child with autism in an ordinary school]. School Psychologist, 2002.

14. Nikol'skaya O.S., Baenskaya E.R., Libling M.M. Autichnyy rebenok: puti pomoshchi [Autistic child: ways to help]. Moscow: Terevinf, 2000. $336 \mathrm{p}$.

15. Nikol'skaya O.S., Baenskaya E.R., Libling M.M. Autichnyy rebenok [Autistic child]. Moscow: Publishing Center "Academy”, 2002. 480 p. 16. Novikova-Ivantsova T.N. Ot slova $k$ fraze [From word to phrase]. Book 1. M, 2006. 
17. Nurieva L.G. Razvitie rechi u autichnykh detey: Metodicheskie razrabot$k i$ [Development of speech in autistic children: Methodological developments]. Moscow: Terevinf, 2003. 160 p.

18. Rumyantseva (Yuntunen) O.A., Starosel'skaya N.E. Nachal'nyy etap korrektsionnoy raboty s negovoryashchimi det'mi [The initial stage of correctional work with non-speaking children]. Problemy detskoy rechi - 1996: materialy mezhvuzovskoy konferentsii [Problems of children's speech - 1996: materials of the interuniversity conference], $\mathrm{SPb}$ : Education, 1996.

19. Sobotovich E.F. Rechevoe nedorazvitie u detey i puti ego korrektsii : (deti s narusheniem intellekta i motor. alaliey) [Speech underdevelopment in children and the ways of its correction (children with intellectual disability and motor alalia)]. M.: Classic style, 2003. $160 \mathrm{p}$.

20. Spivakovskaya A. Psikhoterapiya: igra, detstvo, sem'ya [Psychotherapy: play, childhood, family]. M., April Press, EKSMO - Press, 2000.

21. Shipitsina L.M. Detskiy autizm [Children's autism]. M.: Didactika Plus, 2001.

22. Yaroshevskiy M.G., Petrovskiy A.V. Kratkiy psikhologicheskiy slovar' [Brief psychological dictionary]. A.-M.: Infra-M, 1998.

23. Lovaas I.O. Teaching Individuals with Developmental Delays: Basic Intervention Techniques, Austin, Texas: PRO-ED, Inc., 2003.

24. M. Welch «Holding-Time». N.Y., 1988.

25. Schopler E., Reichler R., Lansing M. Teaching strategies for parents and professionals. Austin, TX: PRO-ED Inc.: 1980.

26. The Picture Exchange Communication System Training Manual, 2nd Edition by Lori Frost, M.S., CCC-SLP and Andy Bondy, Ph.D., 2002, 396 p.

\section{ДАННЫЕ ОБ АВТОРАХ}

Чигинцева Елена Геннадьевна, доцент кафедры дошкольного и специального образования, кандидат педагогических наук, доцент Магнитогорский государственный технический университет им. Г.И. Носова

пр. Ленина, 26, г.Магнитогорск, 455000, Российская Федераџия elchin2864@gmail.com 
Сунагатуллина Ирина Ириковна, доцент кафедры дошкольного и специального образования, кандидат педагогических наук, доцент

Магнитогорский государственный технический университет им. Г.И. Носова

пр. Ленина, 26, г.Магнитогорск, 455000, Российская Федерация vocxod@list.ru

Исаева Елена Викторовна, доцент кафедры дошкольного и специального образования, кандидат педагогических наук

Магнитогорский государственный технический университет им. Г.И. Носова

пр. Ленина, 26, г.Магнитогорск, 455000, Российская Федерация maglena2@yandex.ru

Аболмасова Лиана Сергеевна, магистрант

Магнитогорский государственный технический университет им. Г.И. Носова

пр. Ленина, 26, г.Магнитогорск, 455000, Российская Федераџия dgigarik@mail.Ru

\section{DATA ABOUT THE AUTHORS}

Chigintseva Elena Gennadievna, Associate Professor of the Department of Preschool and Special Education, Candidate of Pedagogical Sciences, Assistant Professor

Magnitogorsk State Technical University

26, Lenin Ave., Magnitogorsk, 455000, Russian Federation

elchin2864@gmail.com

ORCID: 0000-0002-7022-9666

Sunagatullina Irina Irikovna, Associate Professor of the Department of Preschool and Special Education, Candidate of Pedagogical Sciences, Assistant Professor Magnitogorsk State Technical University 
26, Lenin Ave., Magnitogorsk, 455000, Russian Federation vocxod@list.ru

ORCID: 0000-0002-5751-8906

Isayeva Elena Viktorovna, Associate Professor of the Department of Preschool and Special Education, Candidate of Pedagogical Sciences Magnitogorsk State Technical University

26, Lenin Ave., Magnitogorsk, 455000, Russian Federation maglena2@yandex.ru

ORCID: 0000-0002-5872-2191

\section{Abolmasova Liana Sergeevna, Magistrant}

Magnitogorsk State Technical University

26, Lenin Ave., Magnitogorsk, 455000, Russian Federation dgigarik@mail.ru

ORCID: 0000-0001-8935-9535 